below this. Thus levels below $85 \%$ should not exclude the diagnosis of methemoglobinemia. The arterial blood sample despite this low $\mathrm{Spo}_{2}$ will reveal a normal or even elevated oxygen tension in the patient being provided oxygen. Qualitative measurement of methemoglobin levels are obtained with co-oximetry.

The treatment of methemoglobinemia begins with general supportive care, including oxygen and control of the airway if necessary. Methylene blue given in a dose of 1 to $2 \mathrm{mg} / \mathrm{kg}$ intravenously over 10 minutes is the treatment of choice. Methylene blue is reduced to leukomethylene blue by accepting electrons from NADPH in the presence of NADPH methemoglobin reductase. Leukomethylene blue then acts as an electron donor and nonenzymatically reduces methemoglobin to hemoglobin. ${ }^{3}$ In higher doses, methylene blue can produce side effects including chest pain, dyspnea, tremors, and exacerbation of methemoglobinemia by directly oxidizing hemoglobin to methemoglobin. Methemoglobin levels after administration of methylene blue return to normal levels within 20 minutes to 1 hour. If cyanosis persists beyond 1 hour, a second dose may be given. In severe or refractory cases, exchange transfusion may be used. Patients unresponsive to methylene blue treatment may have a congenital deficiency in either glucose-6-phosphate dehydrogenase or NADPH methemoglobin reductase.
In summary, benzocaine-induced methemoglobinemia should be considered in patients undergoing bronchoscopic study when cyanosis develops that is unresponsive to oxygen and associated with normal to high oxygen tensions. Diagnostic confirmation by means of co-oximetry if available should be performed. Intravenous methylene blue is the treatment of choice in patients who have symptomatic levels or who are at high risk for cardiovascular events. Its use is contraindicated in patients with known glucose-6-phosphate dehydrogenase deficiency. Exchange transfusion should be considered in symptomatic patients with near lethal levels.

\section{REFERENCES}

1. Guertler A, Pearce W. A prospective evaluation of benzocaine-associated methemoglobinemia in human beings. Ann Emerg Med 1994;24:626-30.

2. O'Donohue W, Moss L, Angelillo V. Acute methemoglobinemia induced by topical benzocaine and lidocaine. Arch Intern Med 1980;140:1508-9.

3. Curry S. Methemoglobinemia. Ann Emerg Med 1979;11:21421.

4. Barker S, Tremper K, Hyatt J. Effects of methemoglobinemia on pulse oximetry and mixed venous oximetry. Anesthesiology 1989;70:112-7.

\title{
PULMONARY THROMBOENDARTERECTOMY FOR THE TREATMENT OF PULMONARY EMBOLISM CAUSED BY RENAL CELL CARCINOMA
}

\author{
Patrick Paw, MD, and Stuart W. Jamieson MB, FRCS, San Diego, Calif.
}

Chronic pulmonary embolism with pulmonary hypertension is optimally treated by bilateral pulmonary thromboendarterectomy with the use of cardiopulmonary bypass and profound hypothermic circulatory arrest. ${ }^{1}$ With very few exceptions, chronic pulmonary embolism is a bilateral disease. However, we recently performed a unilateral pulmonary thromboendarterectomy with exploration of the contralateral side for a patient with a chronic

From the Division of Cardiothoracic Surgery, University of California San Diego Medical Center, 200 West Arbor Dr., San Diego, Calif.

Received for publication Dec. 2, 1996; accepted for publication Jan. 23, 1997.

Address for reprints: Stuart W. Jamieson, FRCS, Department of Cardiothoracic Surgery, UCSD Medical Center, 200 West Arbor Dr., No. 8892, San Diego, CA 92103-8892.

J Thorac Cardiovase Surg 1997;114:295-7

Copyright (c) 1997 by Mosby-Year Book, Inc.

$0022-5223 / 97 \$ 5.00+0 \quad \mathbf{1 2 / 5 4 / 8 0 7 3 7}$ pulmonary embolus after a right nephrectomy for renal cell carcinoma.

Clinical summary. The patient is a previously healthy 40-year-old man who was referred for the evaluation and treatment of pulmonary hypertension. Three months earlier he had had chest pain and severe dyspnea on exertion. A ventilation/perfusion scan revealed the absence of perfusion to the entire left lung, with a few areas of subsegmental defects in the right lower lobe. He was initially treated with intravenous streptokinase, but this was discontinued because of a toxic reaction. After systemic anticoagulation, a computed tomographic scan of the abdomen and pelvis revealed a large renal tumor impinging on the inferior vena cava. A cardiac echocardiogram demonstrated normal left ventricular wall function with no evidence of a right atrial or ventricular mass, a lower extremity duplex scan showed no deep venous thrombosis, magnetic resonance imaging of the head showed no abnormalities, and results of a bone scan were negative.

A right nephrectomy was performed. Pathologic examination showed a renal cell carcinoma with invasion into 


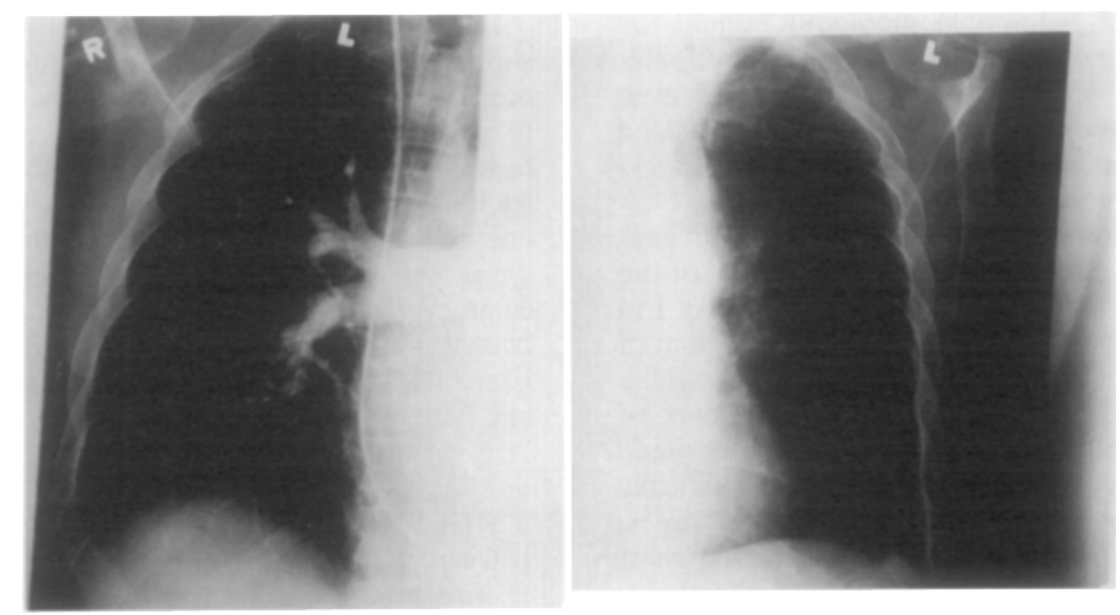

Fig. 1. Pulmonary angiogram with normal blood flow to the right lung and complete occlusion of the left main pulmonary artery.

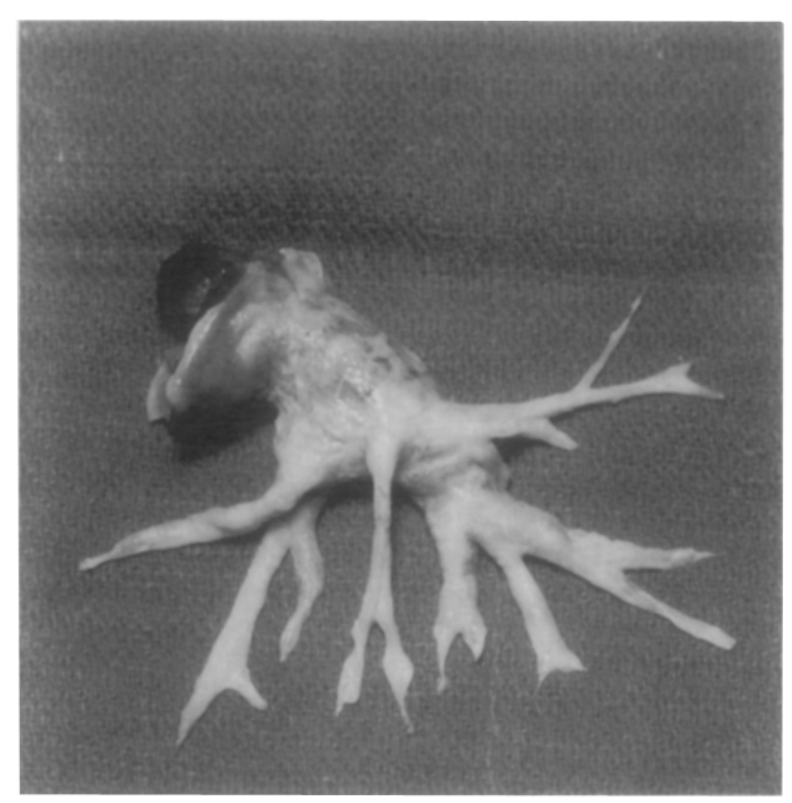

Fig. 2. Thromboendarterectomy specimen removed from the left main pulmonary artery.

the renal vein. Lymph nodes were not diseased. The patient was transferred to our medical center for further diagnostic workup. He still had severe dyspnea on exertion. A second ventilation/perfusion scan confirmed the lack of perfusion to the left lung. Results of pulmonary function tests were consistent with a mild restrictive defect (diffusing capacity for carbon monoxide of 21.5 or $65 \%$, total lung capacity of $5.59 \mathrm{~L}$ or $79 \%$, and normal flow rates). Blood gases with the patient breathing room air were 7.38/83/39 with no desaturation during exercise.

Preoperative catheterization of the right side of the heart demonstrated normal right-sided pressures at rest and a marginally elevated pulmonary vascular resistance $\left(162\right.$ dynes $\left.\cdot \mathrm{sec} \cdot \mathrm{cm}^{5}\right)$. With exercise, the pulmonary artery pressure increased to $50 / 15 \mathrm{~mm} \mathrm{Hg}$ (mean $30 \mathrm{~mm}$ $\mathrm{Hg}$ ). A pulmonary arteriogram demonstrated complete occlusion of the left main pulmonary artery with normal flow to the right lung (Fig. 1). Pulmonary angioscopy revealed a reddish-gray intraluminal lesion occluding the left main pulmonary artery.

A pulmonary thromboendarterectomy was performed as previously described. ${ }^{1}$ On the left side a large clot with fibrous margins incorporating the intima and media was identified, which occluded the entire left main pulmonary artery. This was removed. The appearances were of a yellow-white fibrinous mass measuring $6 \mathrm{~cm} \times 3 \mathrm{~cm} \times 1.5$ $\mathrm{cm}$ (Fig. 2). No occluding material was found on the right side. The final pathologic examination of the specimen revealed only organized thrombus and embolus with no evidence of tumor.

Postoperatively, the patient had normal hemodynamics and pulmonary vascular resistance, and he remains free of symptoms 2 years after the operation.

Discussion. In a small percentage of cases of acute pulmonary embolism the clot persists in the pulmonary artery and eventually becomes organized into a fibrotic mass resulting in chronic pulmonary hypertension. ${ }^{1}$ In our series of 800 patients operated on for thromboembolic pulmonary hypertension, almost all have had bilateral disease with severe pulmonary hypertension. A few patients had a pulmonary vascular resistance of less than 300 dynes $\cdot \mathrm{sec} \cdot \mathrm{cm}^{5}$ and had unilateral pulmonary artery occlusion with a large dead space resulting in unacceptable dyspnea on exertion, as in this case.

This patient was also unusual in that the embolus derived from a renal tumor. Large-tumor embolization from renal cell carcinoma resulting in vascular compromise occurs infrequently, accounting for only seven of 1248 deaths $(0.6 \%)$ in one series. ${ }^{2}$ The pathologic finding of clot without evidence of tumor is consistent with previous findings that most of the pulmonary emboli in patients with renal cell carcinoma contain benign fibrinous clot with no gross or microscopic evidence of tumor. ${ }^{3}$ This would suggest that the embolized tumor fragments 
are either destroyed in the pulmonary artery or remain latent within the vessel wall without parenchymal invasion. Tumor pulmonary embolism therefore does not necessarily imply metastatic disease., ${ }^{4,5}$

In this patient the embolic material on the right side was resolved, but not on the left, probably because of total occlusion. The operation restored the circulation to normal, but an embolectomy did not suffice - a true endarterectomy was required because of the fibrotic, chronic nature of the lesion, with distal thrombosis. Operation in this patient resulted in the complete resolution of symptoms and was likely curative. To our knowledge, this is the first known case of removal of renal cell carcinoma embolus by pulmonary thromboendarterectomy.

\section{REFERENCES}

1. Jamieson SW, Auger WR, Fedullo PF, et al. Experience and results with 150 pulmonary thromboendarterectomy opera- tions over a 29 -month period. J Thorac Cardiovasc Surg 1993;106:116-25.

2. Samsonov VA. Thromboembolism and tumor embolism of the pulmonary artery as a cause of death in oncourologic diseases. Arfhiv Patol 1983,45:73-6.

3. Henriksson C, Aldenborg F, Lindberg S, Pettersson S. Pulmonary embolism in renal cell carcinoma with vena cava extension. Scand J Urol Nephrol 1988;22:215-8.

4. Isringhaus $H$, Naber M, Kopper B. Successful treatment of tumor embolism of a hypernephroma with complete occlusion of the left pulmonary artery. Thorac Cardiovasc Surg 1987;35: 65-6.

5. Daughtry JD, Stewart BH, Golding LAR, Groves LK. Pulmonary embolus presenting as the initial manifestation of renal cell carcinoma. Ann Thorac Surg 1977;24:178-81.

\title{
RIGHT HEART BYPASS WITH AN EXTRACARDIAC CONDUIT FOR FUNCTIONALLY SINGLE VENTRICLE WITH ANOMALOUS PULMONARY VENOUS CONNECTION TO THE RIGHT ATRIUM
}

\author{
Charles S. Roberts, MD, Paul Peters, FRCS, and Christopher Lincoln, FRCS, London, United Kingdom
}

Several methods for bypassing the right side of the heart have been reported in the past 40 years. Our usual technique is total cavopulmonary connection as described by de Leval and associates ${ }^{1}$ in 1988 . Herin we present the case history of a child with a functionally single ventricle and totally anomalous pulmonary venous drainage to the right atrium, which necessitated an unusual technique.

Clinical summary. A 2-year-old child was referred to the Royal Brompton Hospital with cyanotic complex congenital heart disease. She had been cyanotic from birth, had become increasingly breathless, and had recurrent chest infections. She had clubbing of the fingers and toes and a loud precordial systolic murmur. Echocardiography and cardiac catheterization revealed bilateral superior venae cavae (SVCs) and a single right-sided inferior vena cava (IVC), isomerism of the right atrial appendages with a large atrial septal defect, a univentricular atrioventricular connection via a common atrioventricular valve to

From the Royal Brompton Hospital, Sydney Street, London, United Kingdom.

Received for publication Jan. 22, 1997; accepted for publication Feb. 10, 1997.

Address for reprints: Christopher Lincoln, FRCS, Royal Brompton Hospital, Sydney Street, London SW3 6NP, United Kingdom.

J Thorac Cardiovasc Surg 1997;114:297-8

Copyright (C) 1997 by Mosby-Year Book, Inc.

0022-5223/97 $\$ 5.00+0 \quad \mathbf{1 2 / 5 4 / 8 1 1 2 2}$ a dominant right ventricle, a hypoplastic left ventricle, double-outlet right ventricle with pulmonary stenosis, and totally anomalous pulmonary venous connection to the right atrium, near the orifice of the SVC. She did not have subaortic stenosis, and the mean pulmonary arterial pressure was $11 \mathrm{~mm} \mathrm{Hg}$.

A conventional total cavopulmonary connection was attempted. Bilateral bidirectional Glenn shunts were constructed. A lateral intraatrial baffle was placed to direct IVC blood to the pulmonary arteries, attempting to avoid the pulmonary venous connection in the right atrium. Nevertheless, when cardiopulmonary bypass was being discontinued, it became evident that pulmonary venous return was obstructed. The baffle was therefore taken down. Postoperatively, right upper lobe consolidation occurred because of apparent obstruction of the pulmonary vein to the lobe. Otherwise, recovery was uneventful and the child was discharged with an arterial oxygen saturation of $80 \%$.

At the age 3 years 10 months, the child underwent a second echocardiogram and cardiac catheterization. The bilateral bidirectional Glenn shunts were patent, mean pulmonary arterial pressure was $9 \mathrm{~mm} \mathrm{Hg}$, and ventricular function was good. Arterial oxygen saturation was $86 \%$. A second operation was undertaken. With the use of a predominantly extracardiac conduit (19 mm polytetrafluoroethylene tube graft), IVC blood was directed to the pulmonary arteries (Fig. 1). The proximal end of the tube graft was sewn to the IVC orifice in the right atrium. A fenestration $4 \mathrm{~mm}$ in diameter was made in the tube graft 